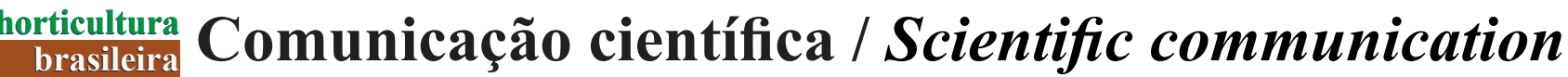

OLIVEIRA FA; DUARTE SN; MEDEIROS JF; DIAS NS; OLIVEIRA MKT; SILVA RCP; LIMA KS. 2015. Nutrição mineral do pimentão submetido a diferentes manejos de fertirrigação. Horticultura Brasileira 33: 216-223. DOI - http://dx.doi.org/10.1590/S0102-053620150000200013

\section{Nutrição mineral do pimentão submetido a diferentes manejos de fertirrigação}

\author{
Francisco A Oliveira ${ }^{1}$; Sergio N Duarte ${ }^{2}$; José F Medeiros ${ }^{1}$; Nildo S Dias ${ }^{1}$; Mychelle KT Oliveira ${ }^{1}$; Ricardo \\ CP Silva ${ }^{1}$; Keivianne S Lima ${ }^{1}$ \\ ${ }^{1}$ UFERSA, Av. Francisco Mota 572, Costa e Silva, 59625-900 Mossoró-RN; thikaoamigao@ufersa.edu.br; jfmedeir@ufersa.edu.br; \\ nildo@ufersa.edu.br; mkto10@hotmail.com; ricarlos_agro@hotmail.com; ²ESALQ, C. Postal 9, 13418-900 Piracicaba-SP; snduarte@ \\ usp.br
}

\section{RESUMO}

O presente trabalho foi desenvolvido em casa de vegetação no Departamento de Ciências Ambientais e Tecnológicas da UFERSA, em Mossoró, RN, com o objetivo de avaliar os teores de macronutrientes em plantas de pimentão submetidas a manejos de fertirrigação e níveis de nitrogênio e potássio. O delineamento experimental adotado foi em blocos casualizados, esquema fatorial $3 \times 6$, com quatro repetições, sendo três manejos de fertirrigação $\left(M_{1}=\right.$ Fertirrigação a partir da marcha de absorção da cultura; $\mathrm{M}_{2}=$ Fertirrigação a partir do monitoramento da concentração de íons de $\mathrm{N}$ e $\mathrm{K}$ na solução do solo; $\mathrm{M}_{3}=$ Fertirrigação a partir do monitoramento da condutividade elétrica da solução do solo) e cinco níveis de nitrogênio e de potássio $\left(\mathrm{N}_{0} \mathrm{~K}_{0}, \mathrm{~N}_{50} \mathrm{~K}_{50}, \mathrm{~N}_{100} \mathrm{~K}_{100}, \mathrm{~N}_{150} \mathrm{~K}_{150}, \mathrm{~N}_{200} \mathrm{~K}_{200}\right.$ e $\left.\mathrm{N}_{300} \mathrm{~K}_{300}\right)$. O nível $\mathrm{N}_{100} \mathrm{~K}_{100}$ corresponde à recomendação de $\mathrm{N}$ e $\mathrm{K}$ para a cultura do pimentão em condição de campo $\left(M_{1}\right)$ e em sistema hidropônico $\left(M_{2}\right.$ e $\left.M_{3}\right)$. Aos 120 dias após o transplantio, as plantas foram coletadas para serem analisadas quanto aos teores de macronutrientes na parte aérea, determinando-se N, P, K, Ca e Mg em folha, caule e frutos. A absorção de nutrientes pelas plantas é variável de acordo com o manejo de fertirrigação adotado. De forma geral, os maiores teores de N, K e Ca ocorreram no tecido foliar; de $\mathrm{P}$ nos frutos e de $\mathrm{Mg}$ no caule. $\mathrm{O}$ manejo da fertirrigação a partir do monitoramento da concentração iônica na solução do solo proporcionou adequada nutrição das plantas com maior economia de fertilizantes.

Palavras chave: Capsicum annuum, cultivo protegido, cápsulas porosas.

\begin{abstract}
Mineral nutrition of sweet pepper under different fertigation management

This study was carried out in a greenhouse at the Universidade Federal Rural do Semi-Árido in Mossoró, Rio Grande do Norte State, Brazil, to evaluate the macronutrient level of bell pepper plants subjected to fertigation management and levels of nitrogen and potassium. The experimental design was randomized blocks in a $3 \times 6$ factorial scheme (three fertigation management forms: $M_{1}=$ fertigation based on the crop mineral absorption, $\mathrm{M}_{2}=$ fertigation by monitoring the concentration of $\mathrm{N}$ and $\mathrm{K}$ ions in the soil solution, $\mathrm{M}_{3}=$ fertigation by monitoring the electrical conductivity of the soil solution) with four replications and five levels of nitrogen and potassium $\left(\mathrm{N}_{0} \mathrm{~K}_{0}\right.$, $\mathrm{N}_{50} \mathrm{~K}_{50}, \mathrm{~N}_{100} \mathrm{~K}_{100}, \mathrm{~N}_{150} \mathrm{~K}_{150}, \mathrm{~N}_{200} \mathrm{~K}_{200}$ and $\mathrm{N}_{300} \mathrm{~K}_{300}$ ). The level $\mathrm{N}_{100} \mathrm{~K}_{100}$ corresponds to the recommendation of $\mathrm{N}$ and $\mathrm{K}$ for growing peppers under field condition $\left(\mathrm{M}_{1}\right)$ and hydroponically $\left(\mathrm{M}_{2}\right.$ and $\left.\mathrm{M}_{3}\right)$. At 120 days after transplanting, plants were collected to be analyzed for macronutrient content in the shoot, determining $\mathrm{N}, \mathrm{P}, \mathrm{K}, \mathrm{Ca}$ and $\mathrm{Mg}$ in leaf, stem and fruit. The absorption of nutrients by plants is variable according to the management of fertigation adopted. In general, the highest levels of N, K and Ca occurred in leaf tissue; phosphorus in fruits and $\mathrm{Mg}$ in the stem. The fertigation management by monitoring the ion concentration in the soil solution provided adequate nutrition of plants with the highest economy of fertilizer.
\end{abstract}

Keywords: Capsicum annuum, greenhouse, porous capsules.

(Recebido para publicação em 11 de abril de 2014; aceito em 16 de dezembro de 2014)

(Received on April 11, 2014; accepted on December 16, 2014)

$\mathrm{O}$ pimentão (Capsicum annuum) é cultivado em todos os estados do Brasil, destacando-se entre as 10 hortaliças mais consumidas no mercado interno. A área plantada no Brasil é de aproximadamente 13 mil hectares, com produção estimada em 290 mil toneladas de frutos (Marouelli \& Silva, 2012); estes autores destacam que os estados de São Paulo, Minas Gerais, Bahia e Rio de Janeiro são os principais produtores nacionais.

Apesar de ser cultivada predominantemente a céu aberto, a produção de pimentão em ambiente protegido vem se expandindo praticamente em todas as regiões do país.

Dentre os mais importantes fatores de produção de pimentão, destaca-se o adequado manejo nutricional, com maior ênfase na quantidade e forma de aplicação dos nutrientes. Trabalhos desenvolvidos com a cultura revelam que o potássio e o nitrogênio são os nutrientes mais exportados pelas plantas (Fontes et al., 2005; Albuquerque et al., 2012; Charlo et al., 2012), sendo também os elementos que mais afetam o rendimento da cultura.

A fertirrigação vem sendo praticada por muitos produtores nas diferentes regiões do país, por permitir um aumento 
na eficiência de absorção de nutrientes pela planta. A fertirrigação torna os nutrientes prontamente disponíveis na solução do solo e fácil de serem absorvidos, uma vez que permite seu parcelamento de acordo com a marcha de absorção da cultura (Marcussi, 2005; Oliveira \& Villas Bôas, 2008).

O nitrogênio e o potássio são os nutrientes aplicados em maior quantidade via fertirrigação, pois apresentam alta solubilidade em água e mobilidade no solo, principalmente, no sentido vertical devido ao efeito promovido pelo fluxo de massa decorrente da percolação de água em decorrência da força gravitacional (Ernani et al., 2007). Assim, apesar de, teoricamente, se aplicar via fertirrigação a quantidade de nutrientes requerida conforme as exigências das plantas, nem todo nutriente fornecido é absorvido por estas, sendo parte deste lixiviado abaixo da zona do solo explorado pelo sistema radicular da cultura (Oliveira et al., 2008).

Além da perda de nutrientes provocada pela lixiviação, a aplicação de um determinado nutriente pode afetar a absorção de um ou mais nutrientes, a exemplo da aplicação excessiva de potássio que pode afetar negativamente

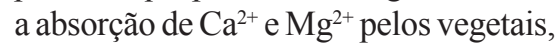
em virtude do efeito antagônico do íon $\mathrm{K}^{+}$(Epstein \& Bloom, 2006).

Existem diferentes formas de manejo para a fertirrigação com o objetivo de monitorar a disponibilidade de nutrientes no solo. A utilização de cápsulas porosas é uma alternativa promissora para detectar a concentração iônica da solução do solo (Silva et al., 2013).

Para que o uso de extratores providos de cápsulas porosas no manejo da fertirrigação possa ser disseminado para os produtores, ainda é necessário o desenvolvimento de mais estudos, principalmente, dando ênfase ao estado nutricional das plantas. Diante do exposto, o presente trabalho foi desenvolvido com o objetivo de avaliar a nutrição mineral de plantas de pimentão submetidas a diferentes manejos de fertirrigação.

\section{MATERIAL E MÉTODOS}

A pesquisa foi desenvolvida no pe- ríodo de junho a novembro de 2010, na Universidade Federal Rural do Semiárido em Mossoró-RN ( $5^{\circ} 11^{\prime} \mathrm{S} ; 3^{\circ} 20^{\prime} \mathrm{O}$, $18 \mathrm{~m}$ de altitude), cuja temperatura média anual é de $27,4^{\circ} \mathrm{C}$, a umidade relativa do ar é de $68,9 \%$ e a precipitação pluviométrica é de $673,9 \mathrm{~mm}$, sendo esta bastante irregular e se concentra nos primeiros meses do ano.

Durante o período experimental, foi realizado o monitoramento de temperatura e umidade relativa do ar no interior da casa-de-vegetação utilizando termohigrômetro digital (Mod. 30.5000.02, TFA Technology HK) instalado no centro da casa-de-vegetação, a uma altura de 1,5 m. As leituras eram realizadas diariamente às 15 horas e a média diária foi calculada pelas expressões: Temperatura do ar $($ Tmed $)=($ Tmax. + Tmin )/2 e Umidade relativa (URmed) $=(\mathrm{URmax}+\mathrm{URmin}) / 2$.

$\mathrm{O}$ experimento foi conduzido em ambiente protegido, utilizando o delineamento em blocos casualizados, em esquema fatorial $3 \times 6$, totalizando 18 tratamentos e com quatro repetições, sendo a unidade experimental representada por um vaso com capacidade para $25 \mathrm{~L}$, com uma planta em cada vaso. Os vasos foram dispostos sobre tijolos de alvenaria com $10 \mathrm{~cm}$ de altura, distribuídos em quatro fileiras espaçadas de $1,5 \mathrm{~m}$, com espaçamento de $50 \mathrm{~cm}$ entre vasos resultando numa população de 13.333 plantas/ha.

Os tratamentos consistiram da combinação de três manejos de fertirrigação $\left(M_{1}=\right.$ fertirrigação a partir marcha de absorção recomendada por Fontes et al. (2005); $\mathrm{M}_{2}=$ fertirrigação a partir do monitoramento da condutividade da solução do solo; $M_{3}=$ fertirrigação a partir do monitoramento da concentração de íons de $\mathrm{N}$ e K na solução do solo); com cinco níveis proporcionais de $\mathrm{N}$ e K $\left(\mathrm{N}_{0} \mathrm{~K}_{0}, \mathrm{~N}_{50} \mathrm{~K}_{50}, \mathrm{~N}_{100} \mathrm{~K}_{100}, \mathrm{~N}_{150} \mathrm{~K}_{150}\right.$, $\mathrm{N}_{200} \mathrm{~K}_{200}$ e $\mathrm{N}_{300} \mathrm{~K}_{300}$ ).

Para o manejo $\mathrm{M}_{1}$ o nível $\mathrm{N}_{100} \mathrm{~K}_{100}$ corresponde às doses de $\mathrm{N}$ e $\mathrm{K}$ recomendadas para a cultura do pimentão na região de Mossoró, correspondente a 215 e $314 \mathrm{~kg} / \mathrm{ha}$ de $\mathrm{N}$ e K.

Para os manejos $\mathrm{M}_{2}$ e $\mathrm{M}_{3}$, o nível $\mathrm{N}_{100} \mathrm{~K}_{100}$ corresponde à concentração de $\mathrm{N}$ e $\mathrm{K}$ recomendada para a cultura do pimentão em sistema hidropônico NFT (152 e $245 \mathrm{mg} / \mathrm{L}$, para N e K, respectivamente), conforme Castellane \& Araújo (1994).

Os níveis de condutividade elétrica $\left(\mathrm{M}_{2}\right)$, e de $\mathrm{N}$ e $\mathrm{K}\left(\mathrm{M}_{3}\right)$ são referentes às concentrações desses nutrientes na solução do solo coletada utilizando os extratores. Desta forma, utilizou-se as curvas de ajuste obtidas em uma prévia calibração (Oliveira et al., 2011) para definição das doses de $\mathrm{N}$ e $\mathrm{K}$ a serem utilizadas nos manejos $\mathrm{M}_{2}$ e $\mathrm{M}_{3}$, sendo definidos os seguintes níveis de condutividade elétrica $(0,6 ; 1,6 ; 2,2 ; 3,1 ; 3,8$ e $4,4 \mathrm{dS} / \mathrm{m})$ e de $\mathrm{N}$ e $\mathrm{K}\left(\mathrm{N}_{0} \mathrm{~K}_{0}, \mathrm{~N}_{76} \mathrm{~K}_{123}\right.$, $\mathrm{N}_{152} \mathrm{~K}_{245}, \mathrm{~N}_{228} \mathrm{~K}_{368}, \mathrm{~N}_{304} \mathrm{~K}_{490}$ e $\mathrm{N}_{380} \mathrm{~K}_{613}$ (mg/L).

O solo utilizado no experimento foi classificado como Argissolo Vermelho Amarelo Distrófico (Embrapa, 2006), do qual foi retirada amostra para caracterização química (Embrapa, 2009), obtendo-se as características: $\mathrm{pH}=5,9$; $\mathrm{MO}=1,05 \% ; \mathrm{P}=2,2 \mathrm{mg} / \mathrm{dm}^{3} ; \mathrm{K}=0,14$, $\mathrm{Na}=0,40, \mathrm{Ca}=0,40, \mathrm{Mg}=0,60, \mathrm{Al}=0,05$ e $\mathrm{H}=2,05 \mathrm{cmol}_{\mathrm{c}} / \mathrm{dm}^{3}$.

Utilizou-se o híbrido 'Atlantis' (Topssed $^{\circledR}$ ), escolhido por ser um dos mais cultivados na região. Foram utilizadas mudas com 35 dias de idade, oriundas de empresa especialista da região.

A irrigação foi realizada por gotejamento, utilizando-se emissores do tipo espaguete com vazão controlada para $1,76 \mathrm{~L} / \mathrm{h}$, e em cada vaso se instalou um espaguete. $\mathrm{O}$ sistema de irrigação foi equipado com caixa d'água suspensa com nível controlado por bóia, linha de derivação, válvulas manuais e linhas laterais.

O cálculo do volume de água para irrigação foi determinado a partir de dados de tensão de água no solo, obtidos através de tensiômetros instalados na profundidade de $15 \mathrm{~cm}$, que foram convertidos em unidade com o auxílio da curva característica de retenção de água no solo $\left\{\mathrm{U}=124,53 \mathrm{~T}^{-0,9419}\right.$, sendo $\mathrm{U}=$ umidade atual do solo $(\mathrm{kg} / \mathrm{kg})$ e $\mathrm{T}=$ tensão matricial do solo $(\mathrm{kPa})\}$. Desta forma, as irrigações foram realizadas aplicando-se o volume de água necessário para elevar a umidade do solo à umidade da capacidade de campo.

Além do tensiômetro, em cada vaso foi instalado um extrator de solução, 
ambos na profundidade de $15 \mathrm{~cm}$, para coleta e monitoramento da solução do solo. As concentrações de nutrientes obtidas na solução coletada pelos extratores eram corrigidas para umidade na capacidade de campo.

Foram realizadas adubações de cobertura via fertirrigação ao longo do ciclo da cultura. Para o manejo $M_{1}$ foram realizadas fertirrigações a cada quatro dias, de acordo com a marcha de absorção da cultura (Fontes et al., 2005). As soluções de fertilizantes eram aplicadas em cada vaso individualmente, utilizando um Becker de $500 \mathrm{~mL}$, aplicando-se o mesmo volume de solução por vaso, tomando-se o cuidado para não molhar o colo das plantas. Utilizaram-se como fontes de nutrientes os fertilizantes: nitrato de cálcio, cloreto de potássio, fosfato monobásico de potássio, nitrato de potássio, nitrato de sódio, cloreto de cálcio, sulfato de magnésio e ácido fosfórico.

Para os manejos $\mathrm{M}_{2}$ e $\mathrm{M}_{3}$, as fertirrigações eram realizadas de acordo com as análises das soluções coletadas com os extratores, fazendo-se a reposição quando a condutividade elétrica $\left(\mathrm{M}_{2}\right)$ ou concentração de $\mathrm{N}$ e $\mathrm{K}\left(\mathrm{M}_{1}\right)$ era reduzida em $20 \%$. O volume de solução aplicado em cada evento de fertirrigação foi o suficiente para elevar a umidade atual do solo à umidade da capacidade de campo.

Nos tratamentos que não continham nitrogênio e potássio $\left(\mathrm{N}_{0} \mathrm{~K}_{0}\right)$ foram aplicados os demais nutrientes, a fim de se obter resposta das plantas apenas às variações nos níveis de $\mathrm{N}$ e $\mathrm{K}$.

A quantidade acumulada de $\mathrm{N}$ e $\mathrm{K}$ aplicados durante o experimento, até o final do mesmo, é apresentada a seguir, em g/planta. Para $\mathrm{M}_{1}, \mathrm{~N}_{0} \mathrm{~K}_{0}=$ 0 e $0 ; \mathrm{N}_{50} \mathrm{~K}_{50}=6,00$ e 6,$65 ; \mathrm{N}_{100} \mathrm{~K}_{100}=$ 11,65 e 13,$29 ; \mathrm{N}_{150} \mathrm{~K}_{150}=17,47$ e 19,55 ; $\mathrm{N}_{200} \mathrm{~K}_{200}=23,33$ e 26,$59 ; \mathrm{N}_{300} \mathrm{~K}_{300}=29,16$ e 33,24. Para $\mathrm{M}_{2}, \mathrm{~N}_{0} \mathrm{~K}_{0}=0$ e $0 ; \mathrm{N}_{50} \mathrm{~K}_{50}=$ 3,26 e 8,95; $\mathrm{N}_{100} \mathrm{~K}_{100}=6,58$ e 11,59; $\mathrm{N}_{150} \mathrm{~K}_{150}=10,11$ e 16,$38 ; \mathrm{N}_{200} \mathrm{~K}_{200}=$ 13,88 e 22,$10 ; \mathrm{N}_{300} \mathrm{~K}_{300}=21,68$ e 29,19 . Para $\mathrm{M}_{3}, \mathrm{~N}_{0} \mathrm{~K}_{0}=0$ e $0 ; \mathrm{N}_{50} \mathrm{~K}_{50}=4,06$ e 6,$31 ; \mathrm{N}_{100} \mathrm{~K}_{100}=6,68$ e 10,$41 ; \mathrm{N}_{150} \mathrm{~K}_{150}=$ 8,39 e 12,$92 ; \mathrm{N}_{200} \mathrm{~K}_{200}=11,96$ e 19,00; $\mathrm{N}_{300} \mathrm{~K}_{300}=12,22$ e 19,14 .

Durante o experimento foram realizadas seis colheitas, sendo a primeira 60 dias após o transplantio (DAT) e a última aos 120 DAT. As demais colheitas ocorreram de acordo com a maturação dos frutos. O ponto de colheita adotado foi quando os frutos atingiram tamanho comercial e cor verde escura brilhante.

Ao final do experimento (120 DAS) as plantas foram coletadas e a parte aérea foi separada em caule, folhas e frutos, as quais foram secas em estufa com circulação forçada de ar a temperatura de $65^{\circ} \mathrm{C}$, até apresentarem massa constante e, em seguida determinou-se a produção de massa seca.

Após a desidratação dos tecidos vegetais, procedeu-se à trituração das amostras utilizando um moinho tipo Willey com peneira de $0,85 \mathrm{~mm}$ (20 mesh), e em seguida as mesmas foram acondicionadas em recipientes hermeticamente fechados, obtendo-se a amostra preparada para as análises.

Para obtenção dos teores dos nutrientes foi realizada a digestão sulfúrica como descrita por Tedesco et al. (1995) e as determinações feitas segundo metodologia descrita por Miyazawa et al. (1999): destilação com arrasto de vapores (método Kjeldahl) para o nitrogênio; espectrofotometria com azul-de-molibdato, para o fósforo; fotometria de emissão de chama, para o potássio e espectrofotometria de absorção atômica, para o cálcio e magnésio.

Os dados obtidos foram submetidos à análises de variância e de regressão, considerando-se o nível de probabilidade de 5\% pelo teste F. Para estabelecer um modelo que representasse o fenômeno em estudo, utilizou-se o teste " $\mathrm{t}$ " de Student para testar os coeficientes de regressão, e os coeficientes de determinação $\left(\mathrm{R}^{2}\right)$. As análises estatísticas foram realizadas utilizando o pacote estatístico SISVAR 5.3 (Ferreira, 2011).

\section{RESULTADOS E DISCUSSÃO}

Durante o experimento foram registradas as seguintes variações de temperatura e umidade relativa do ar no interior da casa-de-vegetação: 21,4 a $25,1^{\circ} \mathrm{C}$ para $\mathrm{Tmin} ; 30,1$ a $33,6^{\circ} \mathrm{C}$ para Tmed; 30,3 a $43,1^{\circ} \mathrm{C}$ para Tmax; 15 a $47 \%$ para URmin; 45 a $62 \%$ para URmed; e 72 a $92 \%$ para URmax.
O consumo de águas pelas plantas variou entre os manejos de fertirrigação e entre as proporções de NK. Para o manejo $\mathrm{M}_{1}$, ao final do ciclo da cultura, foram observados consumos médios de 120, 147, 135, 122, 141 e $111 \mathrm{~L} /$ planta, para os níveis $0,50,100,150,200$ e $300 \%$ NK, respectivamente. Para o manejo $\mathrm{M}_{2}$ houve maior diferenciação entre os níveis de $\mathrm{N}$ e $\mathrm{K}$, e ao final do ciclo os maiores valores foram obtidos nos níveis 100 e $150 \%$ NK, com consumo acumulado médio de $161 \mathrm{~L} /$ planta e os menores consumos hídricos ocorreram nos níveis 0 e $50 \%$ NK, com 120 e 138 $\mathrm{L} /$ planta, respectivamente.

Com relação ao manejo $\mathrm{M}_{3}$, verificou-se ao final, do ciclo o maior consumo no nível $150 \% \mathrm{NK}$, com consumo total de $170 \mathrm{~L} /$ planta, enquanto os menores consumos também ocorreram nos níveis 0 e 50\% NK, com 120 e 137 $\mathrm{L} /$ planta, respectivamente.

Verificou-se que houve interação significativa entre os fatores manejos de fertirrigação e níveis de $\mathrm{N}$ e K sobre o teor de $\mathrm{N}$ (folha, caule e fruto), P (caule), K (folha, caule e fruto), $\mathrm{Ca}$ (caule e folhas) e Mg (folha e caule). Quanto aos fatores isolados, verificou-se efeito significativo dos manejos de fertirrigação sobre os teores de $\mathrm{N}$ (folha, caule e fruto), P (caule), $\mathrm{K}$ (folha e caule), $\mathrm{Ca}$ (folha, caule e fruto) e $\mathrm{Mg}$ (folha, caule e fruto). Para os níveis de $\mathrm{N}$ e $\mathrm{K}$, foram observadas resposta significativas para $\mathrm{N}$ (folha, caule e fruto), $\mathrm{P}$ (folha e caule), $\mathrm{K}$ (folha, caule e fruto), Ca (folha e caule) e $\mathrm{Mg}$ (folha, caule e fruto).

Os maiores teores de $\mathrm{N}$ no tecido foliar (TNF) foram estimados para os níveis de 240, 210 e 250\% para $\mathrm{M}_{1}, \mathrm{M}_{2}$ e $\mathrm{M}_{3}$, respectivamente, com teores de 47,4, 38,5 e 33,2 g/kg (Figura 1A). A partir das equações de regressão pôde-se constatar que, a partir do nível 100\% de $\mathrm{N}$ e K, todos os manejos de fertirrigação proporcionaram TNF na faixa considerada adequada e também observadas por Marcussi (2005), que situa-se entre 30 e $60 \mathrm{~g} / \mathrm{kg}$.

Os maiores teores de $\mathrm{N}$ no caule (TNC) ocorreram nos níveis de $225 \%$ de NK para os manejos $\mathrm{M}_{1}$ e $\mathrm{M}_{2}$, com teores de $17,5 \mathrm{~g} / \mathrm{kg}$, enquanto que para o manejo $\mathrm{M}_{3}$ ocorreu no nível de $300 \%$ de $\mathrm{NK}$, com 16,2 g/kg (Figura 1C). Leonardo et 


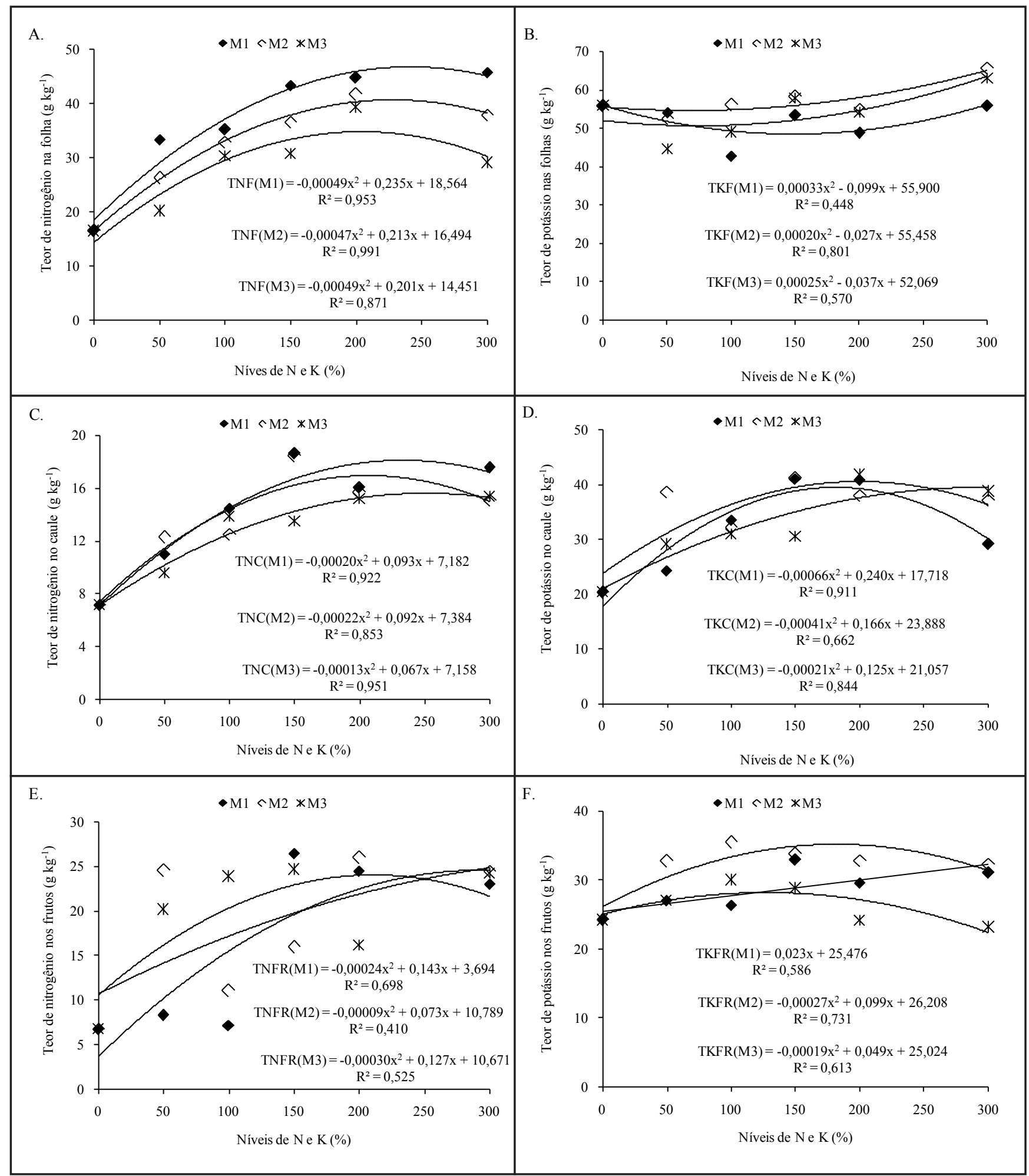

Figura 1. Teor de nitrogênio (A-TNF; C-TNC e E-TNFR) e de potássio (B-TKF; D-TKC e F-TKFR) em plantas de pimentão submetidas a manejos de fertirrigação e níveis de nitrogênio e potássio \{nitrogen content (A-TNF, C-TNC and E-TNFR) and potassium (B-TKF, D- TKC and F-TKFR) in bell pepper plants subjected to fertigation management and levels of nitrogen and potassium \}. Mossoró, UFERSA, 2010.

al. (2008) avaliaram o efeito do estresse salino, produzido por fertilizantes, na cultura do pimentão, híbrido Elisa, e obtiveram TNC de aproximadamente $15 \mathrm{~g} / \mathrm{kg}$, valor bem próximo ao obtido no presente trabalho.

Para o teor de N nos frutos (TNFR), verificou-se que os maiores valores foram obtidos no maior nível de $\mathrm{N}$ e $\mathrm{K}, \operatorname{com} 27,7$ e $22,8 \mathrm{~g} / \mathrm{kg}$, para $\mathrm{M}_{1}$ e $\mathrm{M}_{2}$, respectivamente. Para o manejo $\mathrm{M}_{3}$, foi observado o maior teor de $\mathrm{N}$ no nível de $217 \%$ de NK, com $24,8 \mathrm{~g} / \mathrm{kg}$ (Figura 1E). Albuquerque et al. (2012) observaram em plantas de pimentão (híbrido 
Maximos F1), teores de $\mathrm{N}$ nas folhas e nos frutos de aproximadamente 32,69 e $25,92 \mathrm{~g} / \mathrm{kg}$.

$\mathrm{O}$ aumento na absorção de $\mathrm{N}$ em função do aumento da disponibilidade de $\mathrm{N}$ e $\mathrm{K}$ ocorreu porque existe uma interação de sinergismo entre estes nutrientes, de forma que o aumento nas doses de $\mathrm{K}$ favoreceu a absorção de N. Tal comportamento também foi observado por Ortas (2013), avaliando o efeito de diferentes doses de $\mathrm{N}$ e $\mathrm{K}$ em plantas de pimentão e tomate, onde o autor verificou que o aumento simultâneo destes dois nutrientes resultou em maior absorção de N.

No presente trabalho, avaliando as quantidades de $\mathrm{N}$ e $\mathrm{K}$ aplicadas durante o experimento, percebe-se que houve maior eficiência dos manejos $\mathrm{M}_{2}$ e $\mathrm{M}_{3}$, uma vez que, apesar de aplicar menor quantidade de $\mathrm{N}$, verificou-se nutrição adequada para este nutriente.

O teor de potássio nas folhas (TKF) aumentou em função do aumento de níveis de $\mathrm{N}$ e $\mathrm{K}$, independente do manejo adotado, apresentando em ambos os casos ajuste a equações quadráticas. Foram observados, no maior nível (300\% NK), os TKF de 55,9; 65,35 e 63,47 g/kg, para os manejos $\mathrm{M}_{1}, \mathrm{M}_{2}$ e $\mathrm{M}_{3}$, respectivamente. Comparando-se esses valores com os obtidos na ausência de nitrogênio e potássio $\left(\mathrm{N}_{0} \mathrm{~K}_{0}\right)$, não houve diferença no manejo M1, porém para M2 e M3 ocorreram aumentos de 17,8 e 21,9\%, respectivamente (Figura 1B).

Alves et al. (2009) observaram variação de 45,7 a 49,8 g/kg na cultura do pimentão, cv. All Big. Esses resultados demonstram que as plantas utilizadas neste trabalho apresentaram teores de K no tecido foliar em conformidade com a literatura.

Em relação ao teor de potássio no caule (TKC) foi verificado comportamento quadrático nos três manejos de fertirrigação. Os maiores TKC ocorreram para os níveis de 172, 209 e 300\% de $\mathrm{NK}$, com 38,5; 41,3 e 40,6 g/kg para os manejos $M_{1}, M_{2}$ e $M_{3}$, respectivamente (Figura 1D). Esses valores estão próximos aos encontrados por Marcussi (2005) em pimentão, híbrido Elisa, que verificou TKC variando de 49,0 a 26,3 $\mathrm{g} / \mathrm{kg}$.

Avaliando o efeito dos níveis de $\mathrm{N}$ e K sobre o teor de potássio nos frutos (TKFR), verificou-se comportamento distinto entre os manejos de fertirrigação. Para o manejo $M_{1}$, os dados se ajustaram à equação linear, sendo observado aumento no TKFR em resposta ao incremento nas doses de $\mathrm{N}$ e $\mathrm{K}$, obtendo-se $32,4 \mathrm{~g} / \mathrm{kg}$ para o nível $300 \% \mathrm{NK}$, correspondendo ao aumento de $27,1 \%$ em comparação com os valores obtidos nas plantas que não receberam adubações com N e K (0\% NK) (Figura 1F).

Para os manejos $\mathrm{M}_{2}$ e $\mathrm{M}_{3}$, os dados foram ajustados a equações quadráticas e os maiores valores ocorreram nas proporções 165 e $123 \%$ de NK, com 34,4 e 28,0 g/kg, para os manejos $\mathrm{M}_{2}$ e $\mathrm{M}_{3}$, respectivamente (Figura $1 \mathrm{~F}$ ). Ortas (2013) também verificou aumento na absorção de $\mathrm{K}$ em plantas de pimentão e tomate em reposta à disponibilidade destes nutrientes no solo.

Na literatura são encontrados alguns trabalhos desenvolvidos com a cultura do pimentão, os quais apresentaram teores de $\mathrm{K}$ em frutos variando de 26 a 40,8 g/kg (Marcussi, 2005; Albuquerque et al., 2012), em função da cultivar estudada e épocas de avaliação. Assim, percebe-se que os frutos produzidos no presente experimento apresentaram teores de $\mathrm{K}$ dentro da faixa obtida por esses autores.

Assim como observado para o nitrogênio, também houve maior eficiência na aplicação de potássio em função dos manejos de fertirrigação pois, apesar de se aplicar menores quantidades de potássio, os manejos $\mathrm{M}_{2}$ e $\mathrm{M}_{3}$ proporcionaram adequada concentração de K nas plantas.

Não houve efeito do aumento das doses de $\mathrm{N}$ e $\mathrm{K}$ sobre o teor de fósforo no fruto (TPFR). Entre os tratamentos avaliados, o teor de fósforo nos frutos (TPFR) médio foi de $4,0 \mathrm{~g} / \mathrm{kg}$, próximo ao observado por Albuquerque et al. (2012) em frutos de pimentão, híbrido Elisa, que também não observaram efeito de doses de potássio sobre esta variável, obtendo TPFR médio de 3,75 $\mathrm{g} / \mathrm{kg}$.

Com relação ao teor de fósforo no tecido foliar (TPF), ajustou-se apenas uma equação de regressão para os três manejos de fertirrigação, tendo em vista que não houve efeito significativo da interação entre os fatores sobre esta variável (Figura 2A).

Os dados foram ajustados à equação polinomial de segundo grau, apresentando redução em resposta ao aumento nos níveis de NK, com menor TPF estimado para o nível de 195\% NK (1,7 g/kg), com aumento a partir desta concentração (Figura 2A).

Ainda em relação à Figura $2 \mathrm{~A}$, observa-se maior TPF na ausência de fertirrigação com NK $(5,9 \mathrm{~g} / \mathrm{kg})$, e decréscimo com a aplicação destes nutrientes. Porém, verifica-se que houve pouca variação no TPF entre as proporções de $\mathrm{NK}$, obtendo-se valor médio de 2,6 g/ $\mathrm{kg}$. Estes resultados estão de acordo, em parte, aos obtidos por Albuquerque et al. (2012) para o híbrido de pimentão Elisa, nos quais não se verificaram efeito de duas doses de $\mathrm{K}$ sobre o TPF, ocorrendo TPF médio de $3,38 \mathrm{~g} / \mathrm{kg}$.

Com relação ao teor de fósforo no caule (TPC), foi verificada resposta quadrática no manejo $\mathrm{M}_{1}$, com o maior TPC estimado para o nível de $192 \%$ de $\mathrm{N}$ e K, com 2,4 g/kg. Para os manejos $\mathrm{M}_{2}$ e $\mathrm{M}_{3}$, os dados foram ajustados às equações lineares, sendo o efeito negativo para $\mathrm{M}_{2}$ e positivo para $\mathrm{M}_{3}$ (Figura 2B). Silva et al. (2001) verificaram, ao longo do ciclo de pimentão, teor de $\mathrm{P}$ na parte vegetativo do pimentão (caule + folhas) variando de 2,5 a 2,8 g/ $\mathrm{kg}$, valores bem próximos aos obtidos no presente trabalho.

Avaliando o efeito dos níveis de $\mathrm{N}$ e $\mathrm{K}$ sobre o teor de cálcio nas diferentes partes das plantas, constatou-se resposta variando de acordo com a parte analisada. Para o teor de cálcio nas folhas (TCaF) observou-se de forma geral, que houve redução com o aumento nos níveis de $\mathrm{N}$ e $\mathrm{K}$. Para o manejo $\mathrm{M}_{1}$ os dados foram ajustados à equação quadrática, ocorrendo, inicialmente, redução no $\mathrm{TCaF}$, e nos maiores níveis, tendência de aumento (Figura 2C).

Semelhante ao ocorrido para o manejo $M_{1}$, também houve redução no TCaF nos manejos $\mathrm{M}_{2}$ e $\mathrm{M}_{3}$, no entanto, nesses manejos de fertirrigação, os dados foram ajustados a equações lineares, e foram reduzidos à medida que se aumentou as doses de $\mathrm{N}$ e $\mathrm{K}$, ocorrendo reduções totais de aproximadamente 33,1 e 37,7\% no nível 300\% de $\mathrm{NK}\left(\mathrm{M}_{2}=8,48\right.$ e $\left.\mathrm{M}_{2}=8,82 \mathrm{~g} / \mathrm{kg}\right) \mathrm{em}$ 


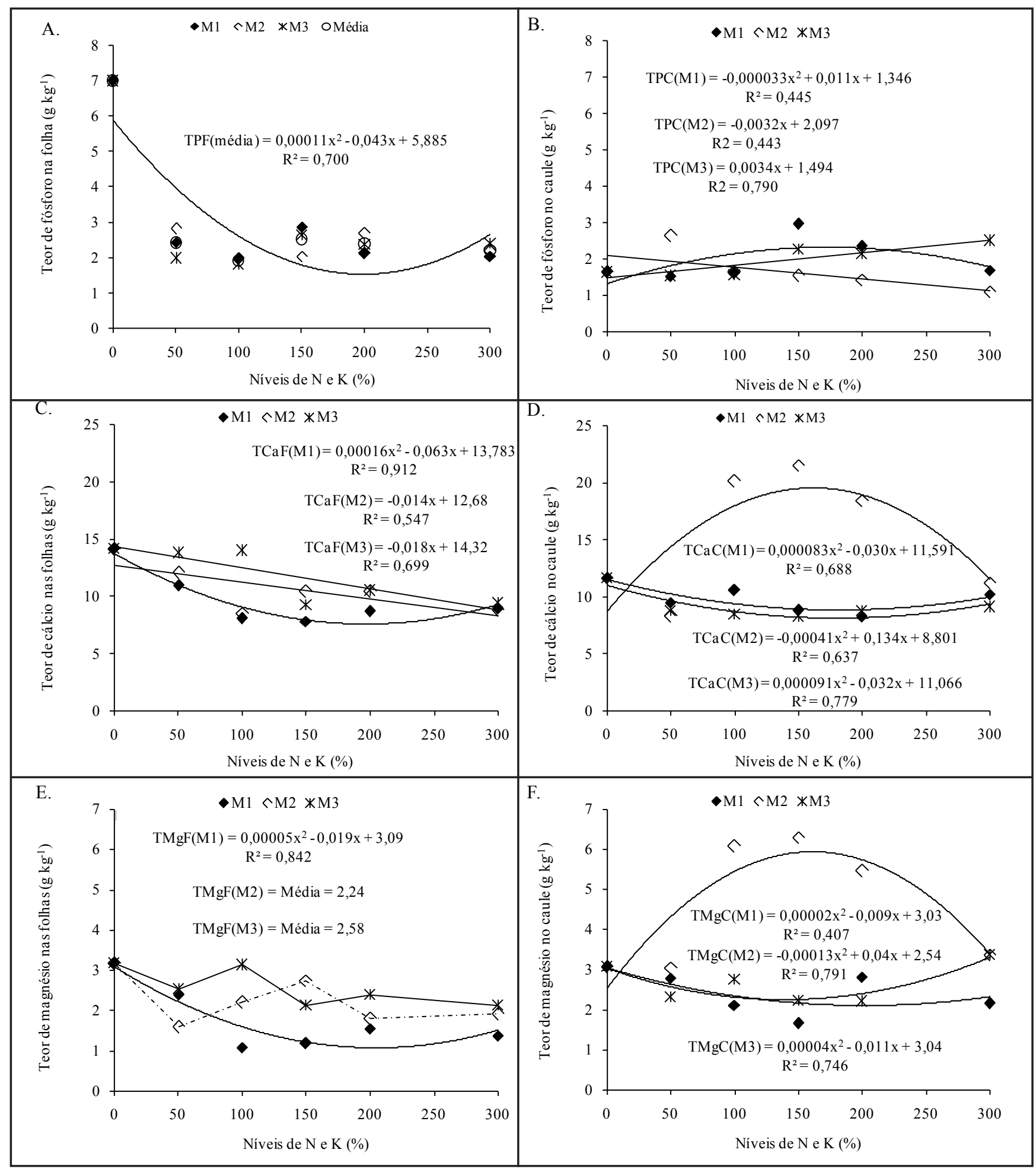

Figura 2. Teor de fósforo (A-TPF e B-TPC), cálcio (C-TCaF e D-TCaC) e de magnésio (E-TMgF e F-TMgC) em plantas de pimentão submetidas a manejos de fertirrigação e níveis de nitrogênio e potássio \{phosphorus content (TPF-A and B-TPC), calcium (C-TCaF and $\mathrm{D}-\mathrm{TCaC})$ and magnesium $(\mathrm{E}-\mathrm{TMgF}$ and $\mathrm{F}-\mathrm{TMgC})$ in pepper plants subjected to fertigation management and levels of nitrogen and potassium\}. Mossoró, UFERSA, 2010.

comparação com os valores obtidos no nível $0 \%$ de NK, para $\mathrm{M}_{2}(12,68 \mathrm{~g} / \mathrm{kg})$ e $\mathrm{M}_{3}(14,32 \mathrm{~g} / \mathrm{kg}$ ) respectivamente (Figura $2 \mathrm{C})$. Esses valores são próximos aos obtidos por Alves et al. (2009), que ob- servaram teor de cálcio no tecido foliar variando de 8,8 a $10,7 \mathrm{~g} / \mathrm{kg}$.

A interação entre $\mathrm{N} \mathrm{e} \mathrm{Ca} \mathrm{nas} \mathrm{plantas}$ é do tipo "sinergismo", de forma que a absorção de $\mathrm{N}$ favorece a absorção de
Ca (Flores et al., 2012). A redução no $\mathrm{TCaF}$ ocorreu, provavelmente, devido ao efeito antagônico do K sobre a absorção de Ca. Neste contexto, Maia (2012) verificou redução linear no TCaF com 
o aumento da concentração de K na solução nutritiva, semelhante ao ocorrido no presente trabalho.

Para o teor de cálcio no caule ( $\mathrm{TCaC})$, verificou-se maior efeito dos níveis de $\mathrm{N}$ e $\mathrm{K}$ para o manejo $\mathrm{M}_{2}$, sendo observado aumento no TCaC até o nível $167 \%$ de NK $(20,0 \mathrm{~g} / \mathrm{kg})$, e decrescendo a partir deste, com 13,0 g/kg no maior nível (300\% de NK), ajustando-se assim à equação quadrática (Figura 2D).

Para os manejos $M_{1}$ e $M_{3}$, observou-se comportamento semelhante, apresentando pequena redução com o aumento nos níveis de $\mathrm{N}$ e $\mathrm{K}$, e tendência de aumento nos maiores níveis, ajustando-se também a equações quadráticas. Nesses manejos foram observados valores variando de 9,34 a 11,59 para $\mathrm{M}_{1}$ e de 8,35 a 11,17 para $\mathrm{M}_{3}$ (Figura 2D). Esses valores são próximos aos obtidos por Marcussi (2005), que avaliou a nutrição do pimentão híbrido Elisa, ao longo do ciclo da cultura e observou $\mathrm{TCaC}$ variando de 6,8 a $13,0 \mathrm{~g} / \mathrm{kg}$.

Não foi observado efeito dos níveis de $\mathrm{N}$ e $\mathrm{K}$ sobre o teor de cálcio nos frutos (TCaFR), sendo obtidos o valor médio de $6,29 \mathrm{~g} / \mathrm{kg}$. De forma geral, os frutos apresentaram menores teores de cálcio em comparação com as folhas e o caule. A translocação de Ca na planta é feita, praticamente, pela corrente transpiratória via xilema e, como consequência, as folhas possuem altas concentrações, e os frutos, baixas concentrações (Epstein \& Bloom, 2006). Estes resultados divergem dos encontrado por Rubio et al. (2009) e Albuquerque et al. (2012), que observaram redução no TCaFR com o aumento das doses de K.

Em relação ao efeito dos níveis de $\mathrm{N}$ e K sobre o teor de magnésio do tecido foliar (TMgF), verificou-se que houve variação de acordo com o manejo de fertirrigação adotado. Para $\mathrm{M}_{1}$ os dados foram ajustados à equação quadrática, verificando-se redução no $\mathrm{TMgF}$ com o aumento nos níveis de $\mathrm{N}$ e $\mathrm{K}$, de forma que os maiores valores ocorreram nas plantas não fertirrigadas $(3,09 \mathrm{~g} / \mathrm{kg})$, reduzindo a partir deste e tendendo a manter-se constante nos demais níveis, apresentando $\mathrm{TMgF}$ médio de $1,56 \mathrm{~g} / \mathrm{kg}$ entre os níveis 100 e $300 \%$ de NK. Para os manejos $\mathrm{M}_{2}$ e $\mathrm{M}_{3}$ não houve efeito dos níveis de $\mathrm{N}$ e $\mathrm{K}$, obtendo-se valores médios de 2,24 e 2,58 g/kg, para $\mathrm{M}_{2}$ e $\mathrm{M}_{3}$, respectivamente (Figura $2 \mathrm{E}$ ).

Em estudo realizado por Rubio et al. (2009) e Albuquerque et al. (2012) com a cultura do pimentão, os autores verificaram também redução no $\mathrm{TMgF}$ em resposta a aumento nas doses de $\mathrm{K}$. De acordo com Malavolta (2006), alta concentração de $\mathrm{K}^{+}$no meio pode inibir competitivamente a absorção de $\mathrm{Mg}$, causando deficiência desse nutriente.

Com relação ao teor de magnésio no caule ( $\mathrm{TMgC}$ ), verificou-se resposta quadrática ao aumento nas doses de $\mathrm{Ne}$ $\mathrm{K}$ nos três manejos de fertirrigação. Para os manejos $\mathrm{M}_{1}$ e $\mathrm{M}_{3}$, houve decréscimo no $\mathrm{TMgC}$ em resposta ao aumento na adubação até determinado nível, com os menores valores obtidos nos níveis 225 e $137 \%$ de NK, com 2,02 e 2,28 $\mathrm{g} / \mathrm{kg}$, respectivamente, apresentando tendência de aumento a partir destes níveis (Figura 2F).

Para o manejo $\mathrm{M}_{2}$ houve aumento no TMgC até o nível $145 \%$ de NK, com $5,62 \mathrm{~g} / \mathrm{kg}$, decrescendo a partir deste (Figura 2F). A redução na absorção de magnésio pelas plantas em resposta ao aumento nas doses de $\mathrm{N}$ e $\mathrm{K}$ ocorreu, provavelmente, devido à inibição competitiva do $\mathrm{Mg}$ com o $\mathrm{K}$, tendo em vista que a interação entre $\mathrm{N}$ e $\mathrm{Mg}$ é do tipo sinergismo (Epstein \& Bloom, 2006).

Avaliando a nutrição de plantas de pimentão ao longo do ciclo, Marcussi (2005) verificou teores de $\mathrm{Mg}$ no caule variando de 3,8 a 8,6 g/ $\mathrm{kg}$; desta forma, apenas o manejo $\mathrm{M}_{2}$ apresentou teores de $\mathrm{Mg}$ próximo aos obtidos por esse autor.

Leonardo et al. (2008) também verificaram efeito significativo ao excesso de fertilizantes sobre a concentração de $\mathrm{Mg}$ no caule e nas folhas de pimentão, em consequência do efeito antagônico ao $\mathrm{K}$, semelhante ao observado para o cálcio.

Não houve efeito dos níveis de $\mathrm{N}$ e K sobre o teor de $\mathrm{Mg}$ nos frutos (TMgFR), sendo obtidos de forma geral, o teor TMgFR médio de 2,44 g/kg. Marcussi (2005) obteve TMgFR variando de 2,4 a $7,7 \mathrm{~g} / \mathrm{kg}$, valores próximos aos obtidos neste trabalho para o manejo $\mathrm{M}_{1}$ e $\mathrm{M}_{2}$. Leonardo et al. (2008) encontraram teor de magnésio nos frutos de pimentão de aproximadamente $2,0 \mathrm{~g} / \mathrm{kg}$.
Avaliando-se a produção de frutos em cada manejo de fertirrigação verificou-se resposta quadrática para os três manejos, obtendo-se as seguintes equações: $\operatorname{PROD}(\mathrm{M} 1)=$ $-0,032 \mathrm{x}^{2}+8,165 \mathrm{x}+804,7\left(\mathrm{R}^{2}=0,712\right)$; PROD $(M 2)=-0,018 x^{2}+8,010 x+709,8$ $\left(\mathrm{R}^{2}=0,627\right) ; \quad$ PROD $(\mathrm{M} 3)=$ $-0,014 \mathrm{x}^{2}+6,019 \mathrm{x}+828,8\left(\mathrm{R}^{2}=0,550\right)$.

Os níveis de $\mathrm{N}$ e $\mathrm{K}$ que proporcionaram as máximas produções de frutos de $1.842,2.488$ e $2.119 \mathrm{~g} /$ planta foram de 127,222 e $214 \%$ de NK, para os manejos $M_{1}, M_{2}$ e $M_{3}$, respectivamente.

Conforme descrito anteriormente, os maiores teores de $\mathrm{N}$ no tecido foliar ocorreram para os níveis de 240, 210 e $250 \%$ para $M_{1}, M_{2}$ e $M_{3}$, enquanto que os maiores teores de $\mathrm{K}$ ocorreram no nível $300 \%$ para os três manejos de fertirrigação. Desta forma, pode-se observar que, para os manejos $\mathrm{M}_{2}$ e $\mathrm{M}_{3}$, o aumento nos teores de $\mathrm{N}$ e $\mathrm{K}$ foram acompanhados pelo incremento na produção, fato este que não foi observado para o manejo $M_{1}$.

Os resultados obtidos neste trabalho demonstram a importância do adequado manejo da fertirrigação na cultura do pimentão, bem como a eficiência do manejo a partir do monitoramento da solução do solo, permitindo maior controle da concentração de sais e favorecendo a absorção de nutrientes pelas plantas. Os maiores teores de nutrientes são analisados com doses de $\mathrm{N}$ e $\mathrm{K}$ variando entre 200 e $250 \%$ da dose recomendada para a cultura e, os manejos de fertirrigação a partir do monitoramento da concentração iônica na solução do solo $\left(\mathrm{M}_{2} \mathrm{e}\right.$ $\mathrm{M}_{3}$ ) proporcionam maior eficiência da aplicação de N e K, obtendo-se adequados teores destes nutrientes mesmo aplicando menores quantidades.

\section{REFERÊNCIAS}

ALBUQUERQUE FS; SILVA EFF; BEZERRA NETO E; SOUZA AER; SANTOS AN. 2012. Nutrientes minerais em pimentão fertirrigado sob lâminas de irrigação e doses de potássio. Horticultura Brasileira 30: 681-687.

ALVES GS; SANTOS D; SILVA JA; NASCIMENTO JAM; CAVALCANTE LF; DANTAS TAG. 2009. Estado nutricional do pimentão cultivado em solo tratado com diferentes tipos de biofertilizantes. Acta Scientiarum. Agronomy 31: 661-665.

CASTELLANE PD; ARAUJO JC. 1994. Cultivo sem solo: hidroponia. Jaboticabal: FUNEP. 
$43 \mathrm{p}$.

CHARLO HCO; OLIVEIRA SF; VARGAS PF; CASTOLDI R; BARBOSA JC; BRAZ LT. 2012. Accumulation of nutrients in sweet peppers cultivated in coconut fiber. Horticultura Brasileira 30: 125-131.

EMBRAPA. 2009. Manual de análises químicas de solos, plantas e fertilizantes. Embrapa Informação Tecnológica. 2. ed. Brasília. 627p.

EMBRAPA. Centro Nacional e Pesquisa em Solos. 2006. Sistema brasileiro de classificação de solos. 2. ed. Rio de Janeiro: Embrapa Solos. $306 \mathrm{p}$.

EPSTEIN E; BLOOM A. 2006. Nutrição mineral de plantas: Princípios e perspectivas. Londrina: Planta. 403p.

ERNANI PR; BAYER C; ALMEIDA JA; CASSOL PC. 2007. Mobilidade vertical de cátions influenciada pelo método de aplicação de cloreto de potássio em solos com carga variável. Revista Brasileira de Ciência do Solo 31: 393-402.

FERREIRADF. 2011. Sisvar: a computer statistical analysis system. Ciência e Agrotecnologia 35: 1039-1042.

FLORES RA; ALMEIDA TBF; POLITI LS; PRADO RM; BARBOSA JC. 2012. Crescimento e desordem nutricional em pimenteira malagueta cultivada em soluções nutritivas suprimidas de macronutrientes. Revista Brasileira de Ciências Agrárias 7: 104-110.

FONTES PCR; DIAS EN; GRAÇA RN. 2005. Acúmulo de nutrientes e método para estimar doses de nitrogênio e de potássio na fertirrigação do pimentão. Horticultura
Brasileira 23: 275-280.

LEONARDO M; BROETTO F; VILLAS BÔAS RL; MARCHESE JA; TONIN FB; REGINA M. 2008. Estado nutricional e componentes da produção de plantas de pimentão conduzidas em sistema de fertirrigação durante indução de estresse salino em cultivo protegido. Bragantia 67: 883-889.

MAIA JTLS. 2012. Cultivo hidropônico do tomateiro do grupo cereja: crescimento, produção e qualidade sob doses de K e sintomas visuais e anatomia sob omissão de nutrientes. Viçosa: UFV. 90p (Tese doutorado).

MALAVOLTA E. 2006. Manual de nutrição mineral de plantas. São Paulo: Ed. Ceres. $630 \mathrm{p}$.

MARCUSSI FFN. 2005. Uso da fertirrigação e teores de macronutrientes em planta de pimentão. Engenharia Agrícola 25: 642-650.

MAROUELLI WA; SILVA WLC. Irrigação na cultura do pimentão. $1^{\text {a }}$ Ed. Brasília: Embrapa, 2012, 20p (Circular Técnica, 101).

MIYAZAWA M; PAVAN MA; MURAOKA T; CARMO CAFS; MELLO WJ. 1999. Análises químicas de tecido vegetal. In: SILVA FC (org). Manual de análises químicas de solos, plantas e fertilizantes. Brasília: EMBRAPA. p. 172-223.

OLIVEIRA FA; MEDEIROS JF; LIMA CJGS; DUTRA I; OLIVEIRA MKT. 2008. Eficiência agronômica da fertirrigação nitrogenada e potássica na cultura do meloeiro nas condições do semiárido nordestino. Revista Caatinga 21: 5-11.

OLIVEIRA FA; MEDEIROS JF; DUARTE SN; SILVA JÚNIOR MJ; CAMPELO CM. 2011.
Calibração de extratores providos de cápsula porosa para monitoramento da salinidade e da concentração de íons. Engenharia Agrícola 31: 520-528.

OLIVEIRA MVAM; VILLAS BÔAS RL. 2008. Uniformidade de distribuição do potássio e do nitrogênio em sistema de irrigação por gotejamento. Engenharia Agrícola 28: 95-103.

ORTAS I. 2013. Influences of nitrogen and potassium fertilizer rates on pepper and tomato yield and nutrient uptake under field conditions. Scientific Research and Essays 8: 1048-1055.

RUBIO JS; GARCÍA-SÁNCHEZ F; RUBIO F; MARTÍNEZ V. 2009. Yield, blossom-end rot incidence, and fruit quality in pepper plants under moderate salinity are affected by $\mathrm{K}^{+}$ and $\mathrm{Ca}^{2+}$ fertilization. Scientia Horticulturae 119: 79-87.

SILVA EM; LIMA CJGS; DUARTE SN; BARBOSA FS; MASCHIO R. 2013. Níveis de salinidade e manejo da fertirrigação sobre características da berinjela cultivada em ambiente protegido. Revista Ciência Agronômica 44: 150-158.

SILVA MAG; BOARETTO AE; MURAOKA T; FERNANDES HG; GRANJA FA; SCIVITTARO WB. 2001. Efeito do nitrogênio e potássio na nutrição do pimentão cultivado em ambiente protegido. Revista Brasileira de Ciência do Solo 25: 913-922.

TEDESCO MJ; GIANELLO C; BOHNEN H; VOLKWEISS SJ. 1995. Análises de solo, plantas e outros materiais. 2. ed. Porto Alegre: UFRGS. 174p (Boletim Técnico, 5). 